WSRC-RP-91-603

[ DE93 001898

\title{
Onsite Well Screening with a Transportable Gas Chromatography/Mass Spectrometer System (U)
}

J. Rossabi, B.A. Eckenrode, and B. Owens

Westinghouse Savannah River Company

Savannah River Site

Aiken, SC 29808

Prepared for the U. S. Department of Energy under contract No. DE-AC09-89SR18035 


\title{
Onsite Well Screening with a Transportable Gas Chromatography/Mass Spectrometer System
}

\author{
J. Rossabi ${ }^{1}$, B.A. Eckenrode ${ }^{2}$, and B. Owens ${ }^{2}$ \\ ${ }^{1}$ Westinghouse Savannah River Company \\ Savannah River Site \\ Aiken, SC 29808
}

\author{
2 Viking Instruments Corporation \\ 12007 Sunrise Valley Drive \\ Reston, VA 22091-3406
}

\begin{abstract}
The number of hazardous waste site operations continue to multiply. The requirements for efficient chemical assessment and monitoring of these sites become more stringent daily. As rnore samples are required, the time required for cleanup operations also increases and may make analytical costs prohibitive. Thus improvements in operation efficiency and reduction of cost in evaluating specific sites to minimize or eliminate their toxic effects on the surrounding environment are critical.

For many years a formal policy did not exist for the disposal of waste solvents and other chemicals, thus many of these compounds were disposed of onsite. So long as these materials were contained onsite, they were not considered to pose a threat to the surrounding environment. We have since determined that many of these compounds found their way into the groundwater. Contaminants such as trichloroethylene (TCE) and perchloroethylene (PCE), which were heavily used for cleaning and degreasing purposes, must be monitored. Groundwater wells can be used to define the location and extent of the migration of any contaminant plume and aid in the determination of required cleanup. The major problem is that monitoring of hundreds of wells may be necessary, requiring several hundred samples on a quarterly basis to characterize the degree and extent of any contamination. Onsite analysis of monitoring wells for this characterization of waste operations could provide time savings and significant cost reduction.

Field analyses can provide the required analytical results quickly and at a reduced cost without compromising either sample integrity or data quality. By using onsite analytical instrumentation, such as a field-transportable gas chromatograph/mass spectrometer (GC/MS), screening analyses can be performed to eliminate returning to the laboratory with meaningless samples. The onsite GC/MS will provide qualitative or semi-quantitative information that can significantly simplify subsequent laboratory analyses. The onsite instrument also provides a performance check analysis for either an in-house laboratory or a contract laboratory result. In some cases, a full analytical qualitative and quantitative analysis may not be required, which makes field-portable instrumentation highly desirable and very cost-effective.
\end{abstract}




\section{Field Gas Chromatograph/Mass Spectrometer Instrumentation}

The SpectraTrak ${ }^{\mathrm{TM}} 620$ transportable GC/MS (ST620) was designed by Viking Instruments specifically for field analytical testing. This instrument has many of the features commonly found on powerful laboratory benchtop instruments. Based on the Hewletu-Packard HP5971A quadrupole mass spectrometer, the ST620 incorporates the computing power of the state-of-the-art Chemstation and SpectraScan/ $\mathrm{OS}^{\mathrm{TM}}$ data system with a Windows ${ }^{\mathrm{TM}} 3.0$ graphics user interface. The ST620 includes the following integrated hardware:

- dual GC/membrane interface

- temperature-programmable oven

- two thermal desorbers

- split/splitless injection system with automated cryofocusing (using liquid $\mathrm{CO}_{2}$ ), a sample pump

- sample pump

- mass flowmeter

- 120-Mb hard disk with an SCSI controller

- I/O panel for modem/printer/tape and power connections

The hard disk is adequate for any of the commercial MS libraries, and for the work described here is loacied with the National Institute of Standards Technology (NIS1) library; which contains 54,000 compounds. The data system provides library searching using a probability-based matching algorithm or an algorithm developed at NIST:

\section{Groundwater Well Screening at the Savannah River Site}

In the fall of 1991 Viking Instruments provided a demonstration SpectraTrak ${ }^{\text {TM }}$ 620 Transportable GC/MS (ST620). The ST620 was used to conduct rapid screening of a number of groundwater wells for contaminants known to be present in the low-to-high ppb concentration range. For this demonstration the ST620 was transported in the back of a Chevrolet S10 pickup truck to the various sites where monitoring was desired. The instrument weighs approximately $150 \mathrm{lbs}$ in its protective case and is designed to be transported to onsite work locations.

At the first site, we backed the instrument up to a well and connected a $5-\mathrm{kW}$ power generator (only $1.25 \mathrm{~kW}$ is required for operation). The system was tuned up and ready for operation in 20 minutes. The well water was purged for five minutes (approximately three well volumes), then sampled. A $10-\mathrm{mL}$ water sample was placed in a 22-mL vial that was sealed with a teflon-faced septum and crimp cap. A headspace sample was taken through the septum by a gas-tight syringe and needle. The sample was concentrated for one minute on the ST620's integral trap packed with Tenax ${ }^{\mathrm{TM}}$ - GC 60/80 mesh adsorbent. The trap was subsequently heated to $175 \mathrm{C}^{\circ}$ for 30 seconds in the instrument's injector/desorber and flushed onto a $20-\mathrm{m}$, $0.18-\mathrm{mm}$ i.d., 0.4 micron DB-5 capillary column fitted with a $0.25-\mathrm{mm}$ i.d. uncoated column retention gap. Two compounds were detected and identified under these conditions; TCE and PCE.

We moved to another location where there are several wells used to study the vadose zone in this region of the site. Power was readily available here, and once again, the instrument was pumped down, tuned, and ready in 20 minutes. The first well was known to contain ppm levels of TCE in the gas phase. For this screen, the integral dimethyl silicone membrane interface was used, and certain targeted analytes were identified. A continuous stream of the well headspace gas was drawn through a sampling tube and across the membrane by the onboard $5.2-\mathrm{L} / \mathrm{min}$ pump. During this analysis, a selected ion monitoring acquisition was set up and we observed the relative levels of the targeted analytes in a timed sequence. A spectral library search was performed resulting in probable constituent identification of chloroform and TCE. The detection of dichloroethylene, a suspected by-product of TCE degradation, was of particular importance, and another sample of the well headspace gas was taken. A selected ion monitoring acquisition employing the membrane suggested that dichloroethylene was indeed present. The resulting overlaid ion chromatograms are shown in Figure 1.

Several wells could be sampled easily from this one location. A 30-ft length of tubing was placed in another well, which was then sampled to the instrument onto a blanked Tenax trap for one minute. We thermally desorbed the sample directly onto the $\mathrm{GC}$ as before; the resulting chromatogram is shown in Figure 2. The vapor phase in this well was known to contain low levels of unknown contaminants. Using MS library searching, we identified at least five compounds present in this well headspace sample.

\section{Conclusions}

Successful analyses were performed during these tests, at several well-heads, using only standard transportation for the ST620 and a portable electric generator where necessary for power. These tests demonstrate the effectiveness of onsite analytical measurements using the selectivity and specificity of a GC/MS system. The ST620 is designed to carry out such tests under difficult field conditions with 
start-up times of 20 minutes or less when moved from site to site.

The advantages of having timely information concerning the specific constituents of a sampled environment on site were readily apparent. In particular, the sample integrity is preserved, there is no doubt where the sample came from, and there is little opportunity for the sample to degrade. Component loss or contamination of a sample are virtually eliminated. Based upon immediate test results, operators can concentrate their attention on sites where contamination is found and can characterize a site rapidly and effectively. This reduces the need to revisit or resample at a particular location. The need for laboratory analyses can be reduced to a minimum. For some purposes, onsite GC/MS testing can eliminate the need for laboratory analyses entirely, with great cost and time savings. Having timely onsite information about contaminants can also reduce worker exposure and better information can reduce potential exposure for surrounding personnel.

In addition, onsite testing was greatly facilitated by the instrument's unique ability to perform analyses based upon multiple sampling cycles in the field. For example, we were able to address a range of concentrations by using direct atmospheric sampling or concentrating the sample using the built-in trap and thermal desorption features. The flexibility to select either a broad MS scan or selected ions allowed rapid, yet sensitive, analysis of suspect contaminants from well-head samples. The ease that this instrument can be taken from a laboratory setting to field siu's enables the operator to set up instrumental analysis methods beforehand and then operate these methods, on an expedited basis, in the field. The software has been configured to permit easy operation by non-chemists. The built-in spreadsheet program (Excel ${ }^{\mathrm{TM}}$ ), permits custom reports to be prepared automatically for each sample run.

The SpectraTrak 620 can be a powerful addition to a mobile laboratory, since it requires only minimal electric power, and the compact size of the multiple function package conserves premium benchtop space. Overall, this onsite analytical work demonstrated the efficiency and effectiveness of analytical operations in the field

\section{Acknowledgments}

The information contained in this article as developed during the course of work done under Contract No. DE-AC09-89SR18035 with the U. S. Department of Energy.

SpectraTrak and SpectraScan are registered trademarks of Viking Instruments.

Windows and Excel are registered trademarks of Microsoft Corporation.

Tenax is a registered trademark of Enka N.V., The Netherlands.

Teflon is a registered trademark of E. I. du Pont de Nemours and Company, Inc. 


\section{List of Figures}

Figure 1 The resulting ion current detected for the specific ions of dichloroethylene from groundwater well headspace gas using the membrane interface. These data were acquired with a 100 -ms dwell time on the quadrupole yielding 2.13 cycles per second. The membrane temperature was held at $30^{\circ} \mathrm{C}$.
Figure 2 Total ion chromatogram from a sample concentration GC/MS cycle of groundwater well gas. Data acquisition conditions were as follows: full scan 35-350 amu (1.7 scans/sec), 1 minute sample, desorption at $175^{\circ} \mathrm{C}$ in 0.5 minutes, column held at $30^{\circ} \mathrm{C}$ for 1 minute and ramped to $100^{\circ} \mathrm{C}$ at $5^{\circ} \mathrm{C} / \mathrm{min}$. 


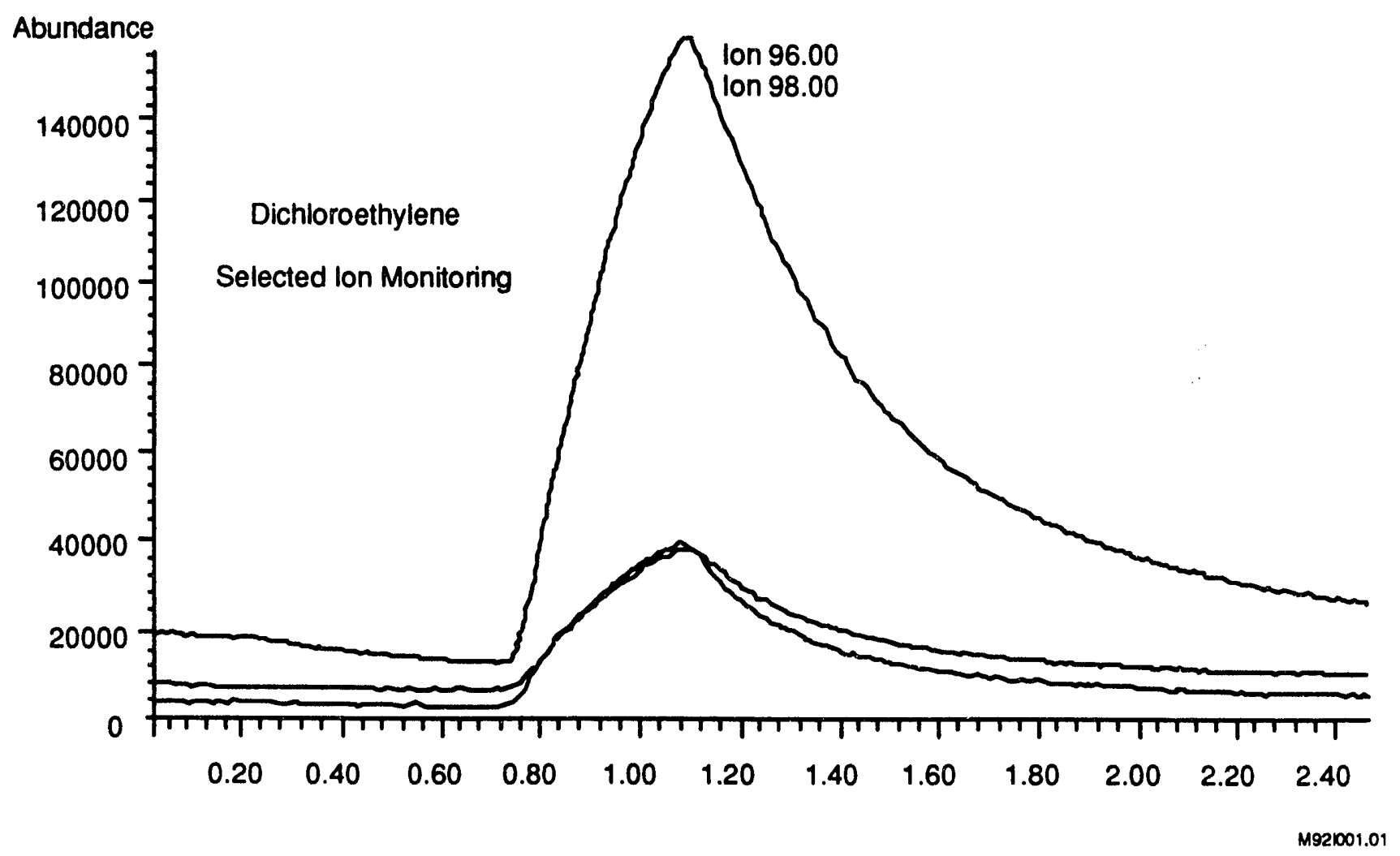

Figure 1. The resulting ion current detected for specific ions of dichloroethylene from groundwater well headspace gas using the membrane interface. These data were acquired with a 100 -ms dwell time on the quadrupole yielding 2.13 cycles per second. The membrane temperature was held at $30^{\circ} \mathrm{C}$. 

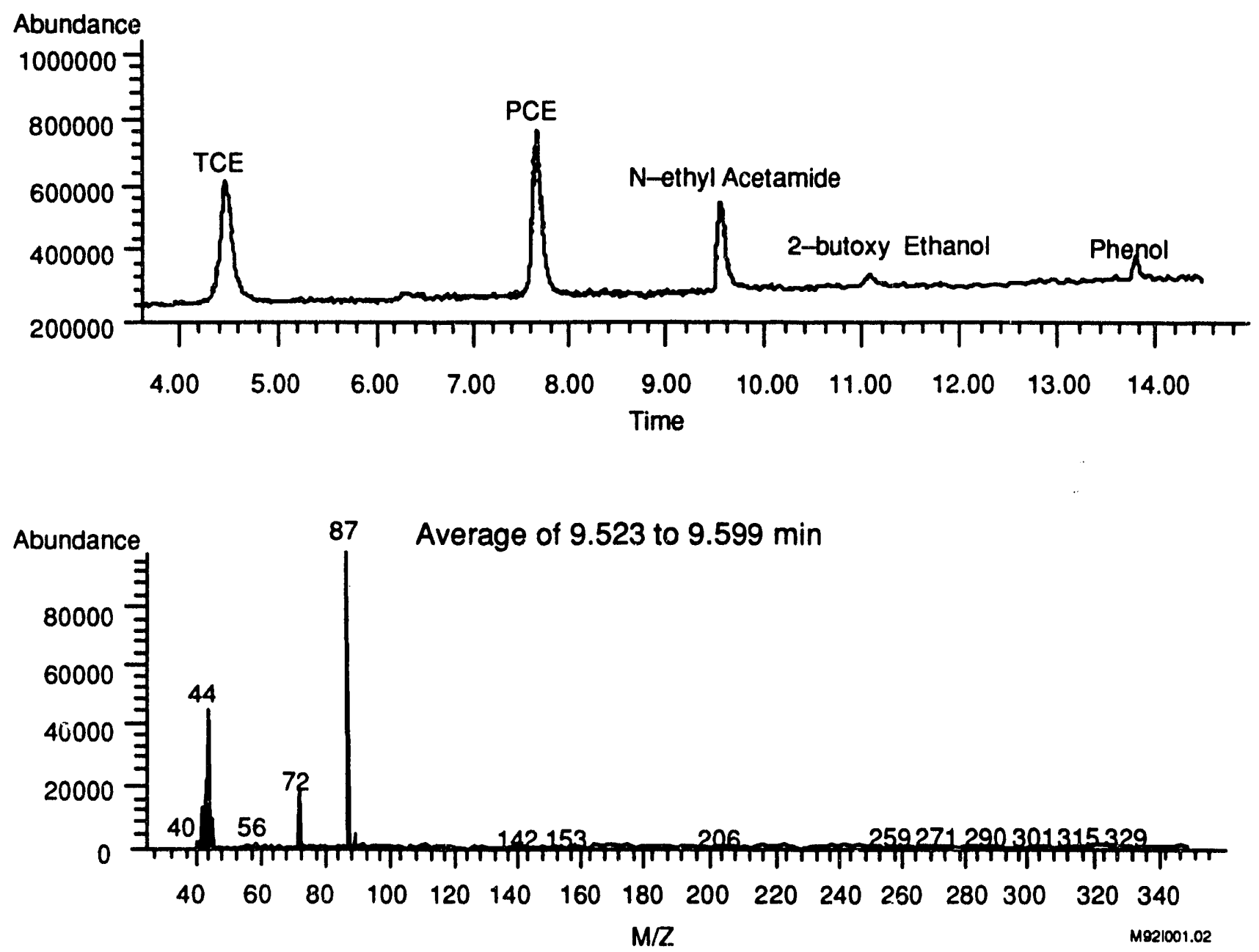

Figure 2. Total ion chromatogram from a sample concentration GC/MS cycle of groundwater well gas. Data acquisition conditions were as follows: full scan 35-350 amu (1.7 scans/sec), 1 minute sample, desorption at $175^{\circ} \mathrm{C}$ in 0.5 minutes, column held a: $30^{\circ} \mathrm{C}$ for 1 minute and ramped to $100^{\circ} \mathrm{C}$ at $5^{\circ} \mathrm{C} / \mathrm{min}$. 

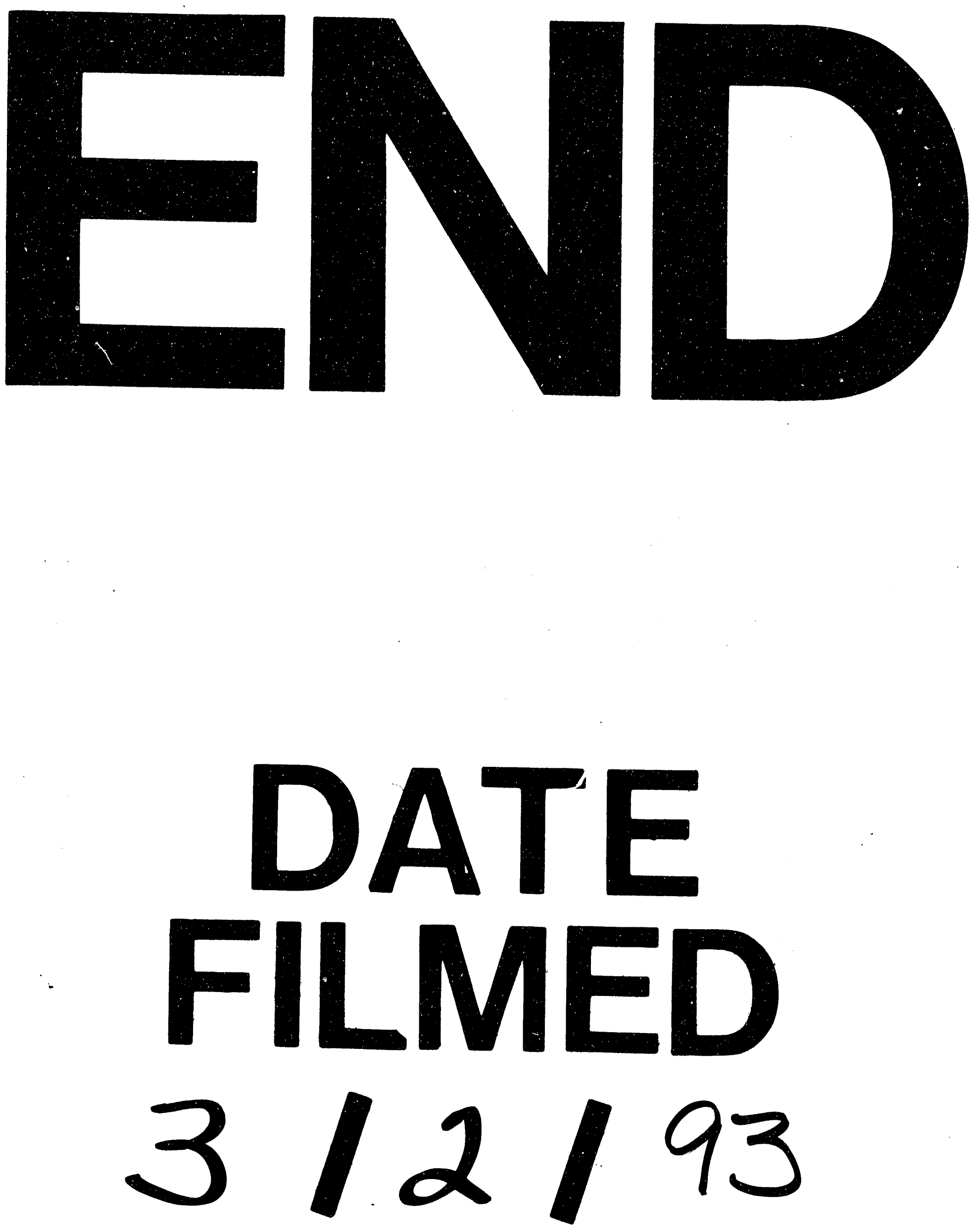
